\title{
THE ROLE OF KNOWLEDGE MANAGEMENT STRATEGIES IN ENHANCING THE CUSTOMER EXPERIENCE FIELD RESEARCH IN SOME IRAQI PRIVATE BANKS
}

\author{
* Lect. Ahmed JadaanHammad, ** Prof. Dr. Salah Al-Deen Al-Kubaisy \\ * University of Tikrit / College of Management and Economics \\ ** University of Baghdad / College of management and Economics
}

DOI: $10.37648 / \mathrm{ij} r s s h . v 10 \mathrm{i} 03.010$

Received: 29 ${ }^{\text {th }}$ May, 2020; Accepted:15 $5^{\text {th }}$ June, 2020; Published: 01 ${ }^{\text {st }}$ July,2020

\section{ABSTRACT}

The purpose of the research is to keep abreast of the scientific developments of its main variables of the research (knowledge management strategies represented by the strategy of personalization and coding, and the customer experience), in addition to conducting a practical analysis to know the relationship between these variables and evaluating the results of the analysis according to the hypothesis of influence. The questionnaire was distributed according to form 78 to the sample banks for the research administrators and their assistants and heads of departments at the headquarters of the banks, (Baghdad, Commercial Iraq, North, United, Middle East, National, Credit, Gulf commercial , )And using (SMART PLS, 3) program. Accordingly, the research reached a set of conclusions that recommend the adoption of knowledge management strategies for the purpose of enhancing the customer experience.

Key words:Knowledge management, strategies personalization strategy, coding strategy, Customer experience.

knowledge, and what is related to tacit knowledge, which

\section{INTRODUCTION}

We live today in a complex and infinite world, and the mind is limited in its ability and understanding of the infinite, in time, space and complexity. Today, researchers and specialists are interested in his great contributions in raising and developing organizations and societies alike, and it has become the basis for business economics, which has made the initial directions for the direction towards knowledge management. With the increase in development in the same field, the researchers 'interest shifted to the realization of a group of hidden and underlying forces behind knowledge management, especially the strategies of coding and personalization of is related to / or derives its roots from the management of strategic human resources at the end of the last century, that it is on Although it is difficult to measure and interpret the invisible powers of man, their credibility is reflected in the increase in individuals who depend on intuition, creativity and the energy inherent in their minds and inspire them with more creative thought that emanates from an unknown source similar to the magical energy that drives achievement and excellence. The research is based on his intellectual originality on the propositions of(AL- faouri, et al, 2011), (Hajric, 2018) on knowledge management and its strategies, and confirm that the work of organizations in the era of knowledge economy is based on their capabilities that qualify them 
to work in The business environment is rapidly changing, which led these organizations to change the traditional thinking frameworks for their work, transforming them into relying on the assets and intellectual and knowledge systems they possess, contrary to what was previously totally dependent on the vision and philosophy of leadership, which gives great importance to this topic and trying to include it as a work platform In Iraqi banks, the customer experience is an interaction between the organization and the customer, it is a mixture of the organization's performance, the stimulating senses, and the feelings that are presented, which are intuitively measured against the expectations of customers at all moments of communication (Aicja, 2013) The customer experience represents the internal and self-response The customer enjoys in every direct or indirect contact with the organization, and this includes every point of contact where the customer deals with the organization (Kenttama, 2014).

\section{THEORETICAL FRAMEWORK}

\subsection{The concept of knowledge management strategies}

The interaction of the strategy with the conditions of the organization and with the competitive environment within which the organization operates, and for this reason knowledge is the strategic source and knowledge management systems are the integral part of the organizational situation (Snyman\& Kruger, 2004: 8).

The first viewpoint looks at strategies that help create, build, store, and use the organization's reliable knowledge (Percin, 2010: 454).

Knowledge management strategies are concerned not only with written or coded knowledge, but also with personal knowledge.

Whereas, the second point of view regards it as the best expected accomplishment of the distinguished knowledge work and achieving the competitive advantage of the organization (Alex, et al, 2012: 210).

Yes, competitive advantage is very important, so if the organization is able to take advantage of knowledge opportunities, it will definitely get a competitive advantage.

As for the third aspect, it is prepared by a set of strategies that achieve the goals and the organization's vision using the clear and implicit knowledge found in the organization (Oluikp, 2012: 863).
Here the words became clearer. Yes, knowledge with its implicit and explicit aspects is the basis for the success of the knowledge strategy.

Or are the methods that enable an organization to develop creative products and services that strategically distinguish it from competitors (Boukis, 2014: 23).

This strategy (Codification strategy) is based on the classification (Hansen et al., 1999), and focuses on the technical side, which plays its role through blogging knowledge in a form of tools, instructions and operations, depending on the support of information technology in using formal methods to acquire, store and share knowledge. The blogging strategy represents (AL-Zeidi, et al, 2016: 41).

This strategy focuses on codifying explicit knowledge and making it available to individuals working in the organization, and this type of knowledge can be stored, distributed and published.

The personalization strategy emphasizes a strategy that emphasizes the underlying nature of knowledge. Knowledge exchange is not just a use of information and communication technology, but it follows the approach of people to people and focuses on dialogue and relationships within the social unit of the organization. Therefore, it is a process of understanding the context that requires human communication and perception in order to emerge. Staff to exchange knowledge depend first and foremost on (AL-faouri, et al, 2011: 3).

\subsection{The concept of customer experience}

The concept of "customer experience" came from the book "The experience of economics" published by Pine and Gilmore in 1999. The book explained the experience as an opportunity to build a new economy that comes after products, services and goods. The first view is that customers experience it as user interactions with products and organizations, or with Other sectors of the organization that catalyze some reactions (Low, et al, 2014: 5)

The second point of view (Grewal \& et al, 2009: 67) It is the first time that the customer tries to interact with the marketing plans and programs carried out by the organization as the customer generates the interaction, which would be a mental image of the organization in the mind of the customer, thus providing services previously And if you were born between them. 
Yes, the customer experience according to the point of view (Grewal \& et al, 2009) is that the customer interacts with the marketing plans and programs that the organization makes in order to have a mental image of the organization, that is, the customer is the initiator of the formation of his experience, but it is not the customer who initiates the formation The experiment alone, as the organization must also take a large initiative in creating the experiment.

As for the third point of view, the customer's experience is seen through generating a feeling, feeling and thinking that the customer is in high contact with the brand of the organization (Verhoef, et al, 2009: 32).The customer experience consists of a set of dimensions Sensory component The environment includes both the internal and external environment of the market. It is the place where the reaction occurs; This includes, for example, the atmosphere and sensory simulations of a service provider such as audio-visual materials, motifs, social and spatial aspects. The direct physical environment is the resource that makes it easier for a customer to do activities with the company (Kenttamaa, 2014: 20).and A cognitive component that involves consumer reasoning or mindful minded processes that may encourage a firm's offer of customers to use thought, creativity and / or problem solving (Stein, 2015: 23) This component is associated with mental processes or thinking. Companies can involve customers in using their creativity or problemsolving skills. Besides, the company can lead the consumer to reconsider the usual idea of a product or some common mental assumptions. This happened, for example, with Barbie, the first doll to portray a young woman (Doorslaer, 2011: 5).and An emotional component The type and strength of emotions that are expressed as a result of interactions between the service provider affects how the experience is perceived, and positive emotions encourage customer loyalty Define the hierarchy of independent emotional groups that influence how the experience is viewed. Recommendation of feelings (such as confidence and feeling of value), and a basis for a positive experience (LOW, 2012,10)This is the intrinsic value, which users see from the association in online merchandise groups. This factor indicates the feelings of excitement among users that are presented in the place where their desired goals represent a vital problem, both brands and products, and the strong association with participation in line with the desired goals to provide users collectively with the context necessary to gain a sense of enjoyment and fun, which can be explained on It's a positive, enjoyable experience that associations may become boring to users over time, which reduces the enjoyable experience rate to a very low level (Sorooshian, et al,2013: 5).and Realistic component The fourth component is derived from the practical verb of doing something. It includes the concept of usability (Apple IMac) is a good example of an amazing practical experience through its design based on the criteria of use, and it does not only refer to the use of the product after purchase, but extends to all product life cycles, (Doorslaer, 2011: 6). And The physical dimension of giving the customer something they do not expect is to exceed the customer's expectations. Exceeding expectations creates happy customers, which means the customer is surprised and happy about the event. However, the cheerful features are unexpected and not expressed by the customer (Kenttamaa, 2014: 20).It depends on the customer experience quality (EXQ). It refers to consumer actions and behavior as a result of interacting with a company or brand that companies target customers' lives through physical experiences, showing them ways to do alternative lifestyle and things (Stein, 2015: 23).

\subsection{Intellectual relationships between knowledge management strategies and customer experience}

It is necessary to integrate emotional knowledge, because it represents unannounced feelings, as it is important for the customer's experience and may be related to other aspects of knowledge (Sun, 2010: 40).

The knowledge of the customer is a personal knowledge with distinction, and with the passage of time this knowledge symbolizes it to become current knowledge or with or explicit knowledge and here comes the role in trying to codify the emotional and sensory aspects in the integration of this knowledge.

The most prominent advantage of knowledge compared to the material and information aspects is that it is the result of human interaction as it is not independent of its surroundings and is generated by individuals in light of their interactions with each other and with the environment on the other side (Nanoaka, 2008: 8), knowing that people make the decision in an emotional way in The Marketplace (Hill, 2008,3),

Emotions and feelings are able to transform into knowledge, and the transformation of emotions into ideas 
allows the study of emotion using cognitive methods (Gladwell, 2005: 71).

Emotions can be transformed into ideas so that they can be studied using the ways in which you can manage ideas.

The interaction between the organization and the customer results from a mixture of the organization's tangible performance, incentives and feelings that are intuitively measured against the customer's experience across moments of communication (Shaw, 2007: 10).

Emotions drive our daily lives and are at the core of existence. In some cases, emotional aspects prevail over mental aspects, as clients make decisions based on their future expectations of what will be on experience, and not based on actual reality.

Studies during the previous years prove that there is a great role for knowledge management in customer experience, and from these studies is a study (Shanks, 2001)

That talked about the role of knowledge management in the transformation of Australian organizations from a focus on the product to focus on the customer and his experience, and this study discussed many issues that include how the use and management of customer information is used, how the customer experience affects business, and what are the organizational changes And the cultural that was introduced to facilitate this matter, that knowledge organizations use their knowledge and experience to make their customers 'experiences successful, and that developing methods of dealing with customers may be seen as a coding strategy for knowledge management, as this study showed that the organization moves from focusing on the product to focusing on the customer Not only uses the coding strategy, but personalization as well (Shanks \& Tay, 2001: 725),

The researchers emphasized (Allamed, et al, 2012: 2) the importance of knowledge management and customer relationship management for the management of customer knowledge, and researchers also emphasized that knowledge management is customer knowledge is a process that helps integrate the customer's experience with knowledge management, and generates an assumption to make the organization's customers partners in generating It is valuable to the organization by providing them with the products and services that they require.
Knowledge management supported by the organization's strategy for excellence, its outputs flow into core business, consolidating and deepening competence and intrinsic ability that cannot be imitated, enabling it to achieve superior performance and continuously generate value for its customers (Shannaak, et al, 2013: 148).

\section{TEST RESEARCH HYPOTHESES}

The first main hypothesis: "There is a significant relationship between knowledge management strategies, customer experience, and superiority," and the following sub-assumptions branch from:

a. There is a significant relationship between coding strategy and customer experience variables (sensory component, emotional component, cognitive component, behavioral component, and physical component).

B. There is a significant relationship between personalization strategy and customer experience variables (sensory component, emotional component, cognitive component, behavioral component, and physical component).

The second main hypothesis: "There is a significant effect of knowledge management strategies on Customer experience.

(First): Test the correlation between the two variables of knowledge management strategies and the customer experience

In this paragraph, correlation relationships based on the research hypothesis are examined between explanatory research variables stating that "there is a significant relationship between knowledge management strategies and the customer experience of the clients" and a group of sub-hypotheses that have been tested and its results are explained in Table (1) that shows the results of the relationship Between knowledge management strategies and customer experience, my agency:

1- The coding strategy showed five positive correlations with the customer experience at a significance $(0.05)$ out of five relationships, which is $100 \%$, and the correlation coefficients were strong and medium except two weak.

2- The personalization strategy showed five positive correlations, at the significance of $(0.05)$ out of five relationships, i.e. $100 \%$ and the correlation coefficients were between medium and weak, and this provides 
sufficient support to accept the second sub-hypothesis from the first major hypothesis, for commercial banks.

3- (a) The total knowledge management strategies with respect to commercial banks showed five positive correlations, at a significance of (0.05) out of five relationships, i.e. $100 \%$, and the correlation coefficients between strong and medium, and thus accept the first major premise at the total level .

Table (1) Correlation coefficients between knowledge management strategies and customer experience, commercial $n$ $=72$

\begin{tabular}{|c|c|c|c|c|c|c|c|c|c|}
\hline \multicolumn{2}{|c|}{$\begin{array}{l}\text { sign relationships } \\
\text { of commercial }\end{array}$} & \multirow{2}{*}{$\begin{array}{l}\text { The } \\
\text { total } \\
\text { custom } \\
\text { er } \\
\text { experie } \\
\text { nce }\end{array}$} & \multirow{2}{*}{$\begin{array}{l}\text { Physic } \\
\text { al } \\
\text { compo } \\
\text { nent }\end{array}$} & \multirow{2}{*}{$\begin{array}{l}\text { Behavi } \\
\text { oral } \\
\text { compo } \\
\text { nent }\end{array}$} & \multirow{2}{*}{$\begin{array}{l}\text { Cognitiv } \\
\text { e } \\
\text { compone } \\
\text { nt }\end{array}$} & \multirow{2}{*}{$\begin{array}{l}\text { Emotio } \\
\text { nal } \\
\text { compo } \\
\text { nent }\end{array}$} & \multirow{2}{*}{$\begin{array}{l}\text { Sensor } \\
\text { y } \\
\text { compo } \\
\text { nent }\end{array}$} & \multirow{2}{*}{\multicolumn{2}{|c|}{$\begin{array}{l}\text { Customer experience } \\
\text { Knowledge } \\
\text { management strategies }\end{array}$}} \\
\hline $\begin{array}{l}\text { Relative } \\
\text { importanc } \\
\text { e }\end{array}$ & $\begin{array}{l}\text { the } \\
\text { numb } \\
\text { er }\end{array}$ & & & & & & & & \\
\hline$\% 100$ & 5 & $0.60 * *$ & $0.65 * *$ & $0.38 * *$ & $0.40 * *$ & $0.38 * *$ & $0.43 * *$ & coding & ategy \\
\hline$\% 100$ & 5 & $* * 0.57$ & $* * 0.55$ & $* * 0.40$ & $0.38 * *$ & $0.40 * *$ & $0.50 * *$ & Persona & zation strategy \\
\hline$\% 100$ & 5 & $0.62 * *$ & $0.64 * *$ & $0.42 * *$ & $0.42 * *$ & $0.41 * *$ & $0.51 * *$ & $\begin{array}{l}\text { Total } \\
\text { manage }\end{array}$ & $\begin{array}{l}\text { knowledge } \\
\text { ent strategies }\end{array}$ \\
\hline- & 15 & 3 & 3 & 3 & 3 & 3 & 3 & $\begin{array}{l}\text { the } \\
\text { numbe } \\
\mathrm{r} \\
\end{array}$ & sign relationships \\
\hline$\% 100$ & & $\% 100$ & $\% 100$ & $\% 100$ & $\% 100$ & $\% 100$ & $\% 100$ & $\begin{array}{l}\text { Relativ } \\
\text { e } \\
\text { import } \\
\text { ance }\end{array}$ & $\begin{array}{l}\text { of commercial } \\
\text { banks }\end{array}$ \\
\hline
\end{tabular}

Source: Preparing the researcher using (SMART PLS3) program.

The second major hypothesis test that says: "There is a significant effect of knowledge management strategies on the customer experience."

Table (2) Results of Influencing Knowledge Management Strategies on Customer Experience of Commercial Banks n $=72$

\begin{tabular}{|l|l|l|l|l|l|l|l|}
\hline \multicolumn{2}{|l|}{ Customer experience. (Z) } & F & Dimensions \\
\hline Significant & $\mathbf{T}$ & Effect & $\mathbf{R}^{\mathbf{2}}$ & $\mathbf{F}$ & $\mathbf{A}$ & \\
\hline Significant & $\mathbf{5 . 6 6 8}$ & Significant & $\mathbf{0 . 4 2 2}$ & $\mathbf{3 2 . 1 2 8}$ & $\mathbf{0 . 4 2 6}$ & $\mathbf{2 . 6 5 2}$ & $\begin{array}{l}\text { Knowledge } \\
\text { 0.426management } \\
\text { strategies }(\mathbf{X})\end{array}$ \\
\hline
\end{tabular}

Source: Preparing the researcher using (SMART PLS3) program.

Table (2) shows the effect of knowledge management strategies on the customer experience of commercial banks, as the calculated value of $(F)$ reached (32.128) which is much greater than its tabular value, indicating the presence of a statistically significant effect, in addition to that the value of the slope coefficient $(\beta)$ of $(0.426)$ indicates that increasing the knowledge management strategy by one unit will work to increase the customer experience by (42\%) and what confirms that the determination factor (R2) reached $(0.422)$, which means what means that the personalization strategy explains $(42 \%)$ of the changes taking place In strategic superiority, either the remaining $58 \%$ is due to factors that are not included in the regression model or uncontrolled factors, i.e. in the processes of perception, judgment, anticipation, thinking, decisionmaking, or action, and this proves the validity of the second major hypothesis. 


\section{CONCLUSIONS}

The research reached a set of conclusions, including the necessity of promoting important changes for the sample of commercial banks with knowledge management strategies to enhance the customer experience, especially by making the customer's journey more enjoyable through the uses of knowledge management strategies as well as the continuation of the banks sample by employing the coding strategy in enhancing the components of the customer experience through developing Knowing the customer, hearing his opinion, and the necessity of the continuation of the banking sample by employing the personalization strategy in introducing more changes in bringing about major changes towards the customer experience.

The need for bank departments to take advantage of the opportunities provided by knowledge management, through the introduction of many methods and methods to enhance the customer experience, and the sample of banks should employ the personalization strategy by encouraging the exchange of explicit and implicit knowledge, and the importance of employing knowledge management, in its ability to influence in Customer experience, given that customers are the cornerstone of any commercial activity.

\section{REFERENCE}

1 Aicja, Pietrasz , (2013) "Achieving Hostel Guest satisfaction customer experience Approach" , instituouniversitariodeliboa, Msc. In science of Business Adminstration, p17

2 Alex,Hou, and Mum Wai, and sabariyah, Binti, and Nooh Abu Baker,(2012), "Integrated knowledge management strategic : A preliminary Literature Review" published by Elservier. Ltd.

3 Allamed, Mohsen, and Shahin, Arash, and Tabanifar,(2012)"Analysis of Relationship between Knowledge Management with Customer Knowledge Management : Case Study At Azaran Company " international Journal of Academic Research in Business and Social Science, V01.2.No.10.

AL-FaouriAbeerHmoud , and Dasguptasubnasish , and Al-Kasasbeh Mohammed Mufaddy. ,(2011),"Investigating the Relationship between knowledge sharing strategies and organization Excellence Pillars" , http:www.Ibimapublishing.com/ journals

AL- Zeidi ,Nadhuim ,JauadAbdSalaman and Komona, Ali Abd Aimer Abd Al- Hussein,(2016), "The Role of Knowledge Management Strategy in Achieving Organization Excellence Filed Research in Sample of Iraq Private Banks ,Journal Business and Management, Vol,18. No,7,pp39-48.

Boukis, Achilleas,(2014), The effect of Internal Market Orientation Internal Dynamics Knowledge management Strategies on NSD project Performance" A thesis submitted to Srathchleyde Business School for the degree of Doctor Philosophy (Ph)in the Department of Marketing.

Doorslaer , Lorenzo Van , (2011) ", customer co-crention and customer experience management" , universities Gent FA culteiteconomieenBedrjfskunde, Master.

7 Grewal . D. , Levy , M. , and Kumar , V. , (2009) "customer experience management in retailing an organizing framework", Journal of retailing , 85 (1) , 1-14.

8 Hajric , Emil , 2018 , "Knowledge management system and vactices", All rights Reserved.

9 Hill, John.\& Johnson, Peter.(2005)," Research Methods for Managers", $3^{\text {rd }}$ ed, SAGE Publication Ltd, London

10 Low , Nick and smart, Andi and Phillips, Laura (2014) "Designing for customer Experience in Non-Hedonic service Conntents : An exploratory study"Journal knowledge management Vol. 3 , No.1, p10.

11 Kenttama , Katraina , (2014) "Identifying and measuring the Dimension of customer experience A study in the Finnish ice cream BAR chain master's thesis", university of OULU, OULU Business school.

12 Nonaka, Ikujiro. Umemoto, Katsabiro and Senoo, Dai.(2008)," from Information Processing to Knowledge creation: A paradigm shift in Business Management", Technology in Society,18(2),Elsevier. 
13 Percin. Selcuk,(2010), "Use of Analytic network Process in Selecting Knowledge Management Strategy" , Group Publish Limited Management Research Review ,Vol.33.No.5,pp:452-471.

14 Stein Alisha ,(2015),"A Real - Time of customer experience" , school of marketing , curtin Business scoll , Thesis . Doctor (ph) philosophy.

15 Sorooshian, Shahryar and Salim Meysam and Saleh Mehrdad and Nia, NeginsadatBekheir (2013) "customer experience about serves quality in online environment: A case of Iran AsfaranianYasha Summand" , precede - Socialand Behavior Sciences vol. 12 , No. 2 .

16 Shannak, Rifat,O, and Masadh, Raed, M, and Mohammod, Ali,(2013), " Knowledge Management Strategy Building :Literature Review", European Scientific Journal ,Vol.8,No.15,

17 Shanks ,G. \&Tay , ,E.,(2001), "Role Knowledge management Moving" , the $9^{\text {th }}$ European Conference in formation system Bled ,Slovenia , June 27-29.

18 Snyman, M.M , and Kruger C.J., (2002), "The interdependence between strategic management and strategic knowledge management" , prentice Both ma and kaniki (Eds) infuse , Pretoria

19 Verhoef, Peter, C. Lemon, Katherine, N. Koggeveen, A. Para suramon Anne, TS. rose Michael and Schlesinger , Leonard , A. ,(2009),"Customer experience (Creation) : Determinant Dyanamics and management strategies" , Journal of Retailing , 85-(1) .pp31-41

20 Oluikp, paul,(2012), Developing Corporate Knowledge Management Strategy " Journal Knowledge Management ,Vol16,Issu, 6. 